\title{
Evaluation of controlled prescriptions with a diagnosis of surgical intervention
}

\author{
Ahmet Akıcı', Mustafa Ümit Uğurlu², İbrahim Topçu³, Hüseyin Yılmazª , Dilek Demircan¹
}

ABSTRACT Objective: Drugs subject to control (DSC) are commonly used in the preoperative, per-operative and postoperative periods. In this study, details of DSC use, that are required to be prescribed to green prescriptions (GP) or red prescriptions (RP), for a surgical diagnosis were evaluated.

Material and Methods: Controlled drug prescriptions (CDP) between January to December 2009 were investigated in the archives of the Istanbul Local Health Authority. 660 CDPs indicating a surgical diagnosis were retrospectively evaluated and those prescribed by surgical departments (SD)were compared to those written by internal medicine departments (ID).

Results: SD physicians prescribed $72.7 \%$ of CDPs and $89.5 \%$ of prescriptions were for GP, and $10.5 \%$ were for RP. The physicians of SD were found to prescribe more RP than ID physicians. Most of the CDPs were written for women (58.8\%) and mostly in private hospitals (40.9\%). Among all the physicians, orthopedic surgeons prescribed these drugs the most (20.9\%). Tramadol was the most common drug found in CDPs (55.5\%).

Conclusion: DSCS, which have difficult prescription procedures, are used frequently in surgical interventions. The study shows that not only SD physicians, but also ID physicians prefer CDP. The study provides important clues to the usage patterns of DSCs. Recently evolving health care systems including prescriptions should use these findings obtained from the study.

Key Words: Surgical intervention, drugs subject to control, green prescriptions, red prescriptions

'Department of Pharmacology, Marmara University Faculty of Medicine, İstanbul, Turkey

2Department of General Surgery, Marmara University Faculty of Medicine, İstanbul, Turkey

${ }^{3}$ istanbul Public Health Center, İstanbul, Turkey

${ }^{4}$ istanbul Directorate of Health, İstanbul, Turkey

\section{Address for Correspondence Dr. Ahmet Akıc} Department of Pharmacology, Marmara University Faculty of Medicine, İstanbul, Turkey Phone.: +90216349 2816 e-mail: aakici@marmara.edu.tr

Received: 10.11.2012

Accepted: 11.01.2013

(C) Copyright 2013 by Turkish Surgical Association

Available online at www.ulusalcerrahidergisi.org

\section{INTRODUCTION}

Drugs subject to control (DSC) include certain psychotropic drugs, and are named as such because they can cause addiction and exhilarating effects. In order to prevent abuse "Narcotic Drugs Single Convention-1961", "Psychotropic Substances Convention-1971" and " the United Nations Convention against Illicit Traffic of Drugs and Psychotropic Substances in-1988 " principles are accepted (1-4). With circulars issued by the Ministry of Health on 01.08 .1985 for narcotic drugs and preparations, a red colored script composed of three copies with self-copy and serial numbers has been used (5). A circular issued in 2003 granted the monitoring and control of these prescriptions to the Local Health Authorities, rather than the Local Pharmaceuticals and Pharmacy Authority (6). According to this act, an original and two copies formed the three copies, and one copy of every prescription for DSC is forwarded to the Local Health Authority monthly and is stored for five years (4-6).

CDP requiring either green prescription (GP) or red prescription (RP) are used commonly especially during surgery and in the postoperative period. Use of these drugs for analgesia is usually planned specific to the patient. For this planning the type of surgery, expected pain severity, the patient's medical condition, patient preference and previous pain experiences are evaluated and analgesic requirements are regulated individually (7). There are various studies referring to the use of DSC throughout the world, and those related to analgesics constitute majority of these studies (8-11). The details of use in DSC in our country remain to be studied.

DSC constitutes an important part of drugs used before, during and after surgical interventions. In this study, we aimed to investigate the details of DSC usage, with a surgical diagnosis by GP or RP.

\section{MATERIAL AND METHODS}

The archives of Istanbul Health Authority for the period of January-December 2009 were examined in this cross-sectional study. A previously formed database for a study regarding comprehensive evaluation of CDP use (drug utilization) in 2009 was used in this study (12). The GP and RPs prescribed for a surgical diagnosis were extracted from this database. Within the selected group of 660 CDPs with a surgical diagnosis those prescribed by surgical departments (SD) and internal medicine departments (ID) were analyzed. 
The copies of CDP, which was sent to the Local Health Authority, were retrospectively reviewed from the period of 01 January 2009 to 31 December 2009 upon obtaining approval from the relevant institutions and Istanbul $3^{\text {rd }}$ Clinical Research Ethics Committee (No. 2009-CC-062). Archived data were included in a way to reflect all the months of the year 2009. In order to cover approximately $10 \%$ of all CDPs in the city, 48,000 prescriptions, in the form of $4000 /$ month prescriptions, were randomly selected. Prescriptions were identified by codes. Keeping patient identification information confidential, prescription details were transferred into a computer program (Excel and SPSS programs). Out of 48,000 CDPs registered in this database, 660 were prescribed with a "surgical intervention" diagnosis. Details of drug use in CDP with any type of surgical diagnosis were investigated. Prescriptions written by SD and ID were compared. No additional procedures were performed to verify information on the prescriptions regarding either the diagnosis or the compliance with drug use.

\section{Statistical Analysis}

Prescribed drugs were evaluated according to the Anatomical Therapeutic Chemical (ATC) classification. Chi-square test and Student's $t$ test were used for statistical comparison. $p<0.05$ was accepted as statistically significant.

\section{RESULTS}

Out of the 660 CDPs, 480 (72.7\%) were prescribed by SD members, while 180 (27.3\%) by physicians from ID. These prescriptions were mostly used in private hospitals (40.9\%), followed by university hospitals (29.1\%), public hospitals (21.9\%), private practice $(5.3 \%)$ and primary care $(2.8 \%)$.

Within the complete group of CDPs with a surgical diagnosis, $89.5 \%$ were on GP, and $10.5 \%$ were on RP and most of these prescriptions were from private hospitals (40.9\%). Although it did not reach statistical significance, it was observed that SD members prescribed more RP as compared to ID members $(11.7 \%$ vs. $7.2 \%$, respectively) ( $p>0.05)$. CDPS were mostly prescribed for women (58.8\%), and gender distribution in members of the SD and ID were found to be similar ( $p>0.05$ ) (Table 1). This demographic similarity was also detected in comparisons concerning patient age ( $p>0.05)$. The mean age of patients in both groups were found to be 43 years (Table 2 ).
In general, prescriptions were deficient on information regarding patient age, reimbursement agency and the amount of active ingredient in the DSC. The CDPs contained information on age in just 206 (31.2\%), and the reimbursement agency information was available in only 164 (24.9\%).

It was seen that more than half of the CDPs (64.6\%) indicating the reimbursement agency belonged to prescriptions controlled by the Social Security Institution (SSI). In both groups, the rate of SSI was high, but this rate was higher in prescriptions by ID physicians than by SD members (78.9\% vs. $57.0 \%$, respectively) (Table 3 ).

In the 660 CDP, 708 DSC has been prescribed. 188 of them (26.6\%) were written by ID physicians, and 520 (73.4\%) by SD members. In $52.4 \%$ of these drugs, the amount of active substance was not written on the prescription. This information was noted less by SD members as compared to ID members (47.6\% vs. $52.7 \%$, respectively).

Stratifying CDPs according to surgical specialty, they were mostly prescribed in orthopedic surgery (28.8\%), neurosurgery (19.6\%), anesthesia (16.9\%) and general surgery (13.5\%). Considering all the evaluated CDPs, the rank according to specialty was similar to the rank in SD. The CDP was prescribed most by orthopedic surgery (20.9\%), neurosurgery (14.2\%), anesthesia (12.3\%) and general surgery (9.8\%). When ID were analyzed within itself, CDP were mostly prescribed by internal medicine (33.3\%) and physical therapy and rehabilitation (16.7\%) (Table 4).

More than one third of (34.8\%) the 708 DSC prescribed were in the pharmaceutical form of tablets, followed by capsules (23.7\%) and injection forms (20.5\%). On analysis of these pharmaceutical forms in the groups, the first line of choice remained the same in SD and Id (Table 5).

When ATC distribution of prescribed drugs subject to control was evaluated, it was found that, the most common drug in CDP was tramadol (N02AX02) (55.5\%). This was followed by midazolam (N05CD08), (12.9\%), alprazolam (N05BA12) (7.2\%), and pethidine (N02AB02) (5.1\%). It was found that in both SD and ID, the most frequently written drug was tramadol $(60.8 \%$

Table 1. Patient gender and type of prescription according to medical department that prescribed the CDP with a surgical diagnosis

\begin{tabular}{|c|c|c|c|c|c|c|c|}
\hline \multirow[t]{2}{*}{ Prescribed by } & & \multicolumn{2}{|c|}{ ID Physicians } & \multicolumn{2}{|c|}{ SD Physicians } & \multicolumn{2}{|c|}{ Total } \\
\hline & & $\mathrm{n}$ & $\%$ & $\mathrm{n}$ & $\%$ & $\mathrm{n}$ & $\%$ \\
\hline \multirow{4}{*}{ Prescription type } & GP & 167 & 92.8 & 424 & 88.3 & 591 & 89.5 \\
\hline & $\mathrm{RP}$ & 13 & 7.2 & 56 & 11.7 & 69 & 10.5 \\
\hline & Total & 180 & 100.0 & 480 & 100.0 & 660 & 100.0 \\
\hline & Statistics & $p>0.05$ & & & & & \\
\hline \multirow{4}{*}{ Gender } & Female & 102 & 57.0 & 278 & 59.5 & 380 & 58.8 \\
\hline & Male & 77 & 43.0 & 189 & 40.5 & 266 & 41.2 \\
\hline & Total & 179 & 100.0 & 467 & 100.0 & 646 & 100.0 \\
\hline & Statistics & $p>0.05$ & & & & & \\
\hline
\end{tabular}


vs. $41.0 \%$, respectively), followed by alprazolam (7.3\%), midazolam (5.6\%), and pethidine (4.6\%) in SD, and by midazolam (33.3\%), phenobarbital (N03AA02), (8.0\%) and alprazolam (6.9\%) in ID (Table 6).

\section{DISCUSSION}

In this study, DSC prescribed by SD and ID physicians were analyzed retrospectively. All CDPS prescribed in Istanbul and delivered monthly to the Local Health Authority from all districts, according to the effective national legislation were evaluated. This analysis was carried out by selecting samples over a 1-year period in a metropolis like Istanbul and it represents the first comprehensive data on this subject, at this level.

Although CDP with a surgical diagnosis were most commonly prescribed by SD physicians (72.7\%), it was found out that in this study a considerable amount of CDPs with such diagnosis were prescribed by ID physicians (27.3\%). The reasons leading to this finding were not investigated in the current study; nevertheless, it may be associated with the postoperative longterm treatment.

On the other hand, the findings that SD physicians prescribe CDP the most (72.7\%) and that analgesic drugs, especially tramadol and pethidine $(60.8 \%$ and $4.6 \%)$ are prescribed at a higher rate, show that these drugs are being used quite often for postoperative analgesia (Table 6) (13).

Prescriptions by ID and SD physicians did not differ in terms of age or gender, and it was found that CDP is most frequently prescribed in private hospitals (Table 1, 2). In the literature, studies indicate that physicians working in the private sector often prescribe this group of drugs, which shows similarities with the situation in our country (14). Although most of the CDPs with a specified reimbursement agency belonged to SSI
(64.6\%), the significant number of prescriptions from private health institutions (46.2\%) supports the aforementioned finding (Table 3). This situation can also be associated with patients' benefiting more from private health institutions in the recent years.

On evaluation of surgical branches in itself, it was identified that orthopedic surgeons (20.9\%) prescribed DSC most commonly, and the most preferred drug was tramadol (N02AX02) (Table 4, 6). The most common preferred pharmaceutical form was the tablet form (35.4\%) (Table 5). DSC use after orthopedic surgery is common all over the world. In a study conducted in the US, the most common preferred drug after orthopedic surgery was noted as morphine (15). In our country, clinicians use morphine sulfate in the oral form in the treatment of cancer pain, and they often prefer weak opioids such as tramadol in other situations. The efficiency of tramadol is generally increased by combining with nonopioids and adjuvant medicine (16). In our study, $55.5 \%$ of DSCs has been found to be tramadol.

There are some limitations to this study. Since the prescriptions were obtained via a direct written copy with neither electronic data nor patient file, further questioning of any issue could not be done. This situation has led to difficulties in confirming the diagnosis. It could not been shown what proportion of the prescriped drugs depended on a rational choice. Only a small number of similar studies are present in the literature. Stiefel et al. (17) evaluated prescriptions by 1,200 physicians, and found the rate of DSC in cancer-related pain and after surgery as $89 \%$. It was reported that $20 \%$ of physicians wrote inappropriate prescriptions. In another multicenter study on postoperative analgesia, it is emphasized that clinicians achieve suboptimal pain control that this leads to patient dissatisfaction and that DSC application should be done more rationally and accord-

Table 2. Patient age according to medical department that prescribed the CDP with a surgical diagnosis

\begin{tabular}{|lcccc|}
\hline & ID physicians & SD physicians & Total & Statistics \\
\hline Mean & 43.25 & 43.13 & 43.17 & $\mathrm{p}>0.05$ \\
\hline Standard deviation & 23.56 & 14.85 & 18.09 & \\
\hline Minimum-maximum & $0-82$ & $1-82$ & $0-82$ \\
\hline $\mathrm{n}$ & 67 & 139 & 206 \\
\hline SD: Surgical Departments, ID: Internal Departments & & &
\end{tabular}

Table 3. Reimbursement agency according to medical department that prescribed the CDP with a surgical diagnosis

\begin{tabular}{|c|c|c|c|c|c|c|}
\hline \multirow[t]{2}{*}{ Prescribed by } & \multicolumn{2}{|c|}{ ID Physicians } & \multicolumn{2}{|c|}{ SD Physicians } & \multicolumn{2}{|c|}{ Total } \\
\hline & $\mathrm{n}$ & $\%$ & $\mathrm{n}$ & $\%$ & $\mathrm{n}$ & $\%$ \\
\hline \multicolumn{7}{|l|}{ Reimbursement Agency } \\
\hline SSI & 45 & 78.9 & 61 & 57.0 & 106 & 64.6 \\
\hline Private Health Insurance & 4 & 7.0 & 19 & 17.8 & 23 & 14.0 \\
\hline Other & 6 & 10.5 & 1 & 0.9 & 7 & 4.2 \\
\hline Not insured & 2 & 3.6 & 26 & 24.3 & 28 & 17.1 \\
\hline Total & 57 & 100.0 & 107 & 100.0 & 164 & 100.0 \\
\hline
\end{tabular}

SD: Surgical Departments, ID: Internal Departments 


\begin{tabular}{|c|c|c|c|c|}
\hline & Specialty & Number of prescriptions & $\%$ & $\% *$ \\
\hline \multirow{10}{*}{ ID Physicians } & Internal Medicine & 60 & 33.3 & 9.1 \\
\hline & Physical Therapy and Rehabilitation & 30 & 16.7 & 4.5 \\
\hline & Pulmonary Disease & 23 & 12.8 & 3.5 \\
\hline & Neurology & 21 & 11.7 & 3.2 \\
\hline & Pediatrics & 14 & 7.8 & 2.1 \\
\hline & Pediatric Pyschiatry & 8 & 4.4 & 1.2 \\
\hline & Physciatry & 7 & 3.9 & 1.1 \\
\hline & Radiology & 6 & 3.3 & 0.9 \\
\hline & Other & 11 & 6.1 & 1.7 \\
\hline & Total & 180 & 100.0 & 27.3 \\
\hline \multirow{10}{*}{ SD Physicians } & Orthopedics & 138 & 28.8 & 20.9 \\
\hline & Neurosurgery & 94 & 19.6 & 14.2 \\
\hline & Anesthesia & 81 & 16.9 & 12.3 \\
\hline & General Surgery & 65 & 13.5 & 9.8 \\
\hline & Otorhinolaryngology & 32 & 6.7 & 4.8 \\
\hline & Obstetrics and Gynecology & 31 & 6.5 & 4.7 \\
\hline & Cardiothoracic Surgery & 17 & 3.5 & 2.6 \\
\hline & Plastic Surgery & 11 & 2.3 & 1.7 \\
\hline & Other & 11 & 2.3 & 1.7 \\
\hline & Total & 480 & 100.0 & 72.7 \\
\hline
\end{tabular}

*Percentage according to total prescription number (660)

SD: Surgical Department, ID: Internal Department

\section{Table 5. Pharmaceutical forms according to medical department that prescribed the CDP with a surgical diagnosis}

\begin{tabular}{|c|c|c|c|c|c|c|}
\hline \multirow[t]{2}{*}{ Prescribed by } & \multicolumn{2}{|c|}{ ID Physicians } & \multicolumn{2}{|c|}{ SD Physicians } & \multicolumn{2}{|c|}{ Total } \\
\hline & $\mathrm{n}$ & $\%$ & $\mathrm{n}$ & $\%$ & $\mathrm{n}$ & $\%$ \\
\hline \multicolumn{7}{|c|}{ Pharmaceutical forms } \\
\hline Pills & 62 & 33.0 & 184 & 35.4 & 246 & 34.8 \\
\hline Capsule & 42 & 22.3 & 126 & 24.2 & 168 & 23.7 \\
\hline Parenteral (ampule) & 56 & 29.8 & 89 & 17.1 & 145 & 20.5 \\
\hline Parenteral (flacon) & 4 & 2.1 & 32 & 6.2 & 36 & 5.1 \\
\hline Dropping & 9 & 4.8 & 38 & 7.3 & 47 & 6.6 \\
\hline Other & 1 & 0.5 & 14 & 2.7 & 15 & 2.1 \\
\hline Not specified & 14 & 7.5 & 37 & 7.1 & 51 & 7.2 \\
\hline Total & 188 & 100.0 & 520 & 100.0 & 708 & 100.0 \\
\hline
\end{tabular}

SD: Surgical Department, ID: Internal Department

ing to guidelines (18). In our study, it was seen that at least a portion of the physicians prescribing CDP do not act rational enough, as they are not filling in all the required formatted information. The lack of information on the amount of active ingredient and prescription format, in this type of retrospectively planned studies, reveals poor performance of physicians on this subject and prevents further analysis to be conducted. In order for a prescription to serve its aim, issue is much more important in CDP that needs specific control and requires physicians to pay more attention on the subject.

Based on the findings obtained in this study and other studies in the literature, it can be said that this issue needs to be explored more in our country. In the future, emphasis on studies particular addressing patients' clinical status and the rationality of drug selection will be useful. 
Table 6. Drugs according to medical department that prescribed the CDP with a surgical diagnosis

\begin{tabular}{|c|c|c|c|c|c|c|}
\hline \multirow[t]{2}{*}{ Prescribed by } & \multicolumn{2}{|c|}{ ID Physicians } & \multicolumn{2}{|c|}{ SD Physicians } & \multicolumn{2}{|c|}{ Total } \\
\hline & $\mathrm{n}$ & $\%$ & $\mathrm{n}$ & $\%$ & $\mathrm{n}$ & $\%$ \\
\hline \multicolumn{7}{|l|}{ Drugs (ATC Code) } \\
\hline Tramadol (N02AX02) & 77 & 41.0 & 316 & 60.8 & 393 & 55.5 \\
\hline Midazolam (N05CD08) & 62 & 33.0 & 29 & 5.6 & 91 & 12.9 \\
\hline Alprazolam (N05BA12) & 13 & 6.9 & 38 & 7.3 & 51 & 7.2 \\
\hline Pethidine (N02AB02) & 12 & 6.4 & 24 & 4.6 & 36 & 5.1 \\
\hline Phenobarbital (N03AA02) & 15 & 8.0 & 8 & 1.5 & 23 & 3.2 \\
\hline Codein (---) & - & - & 23 & 4.4 & 23 & 3.2 \\
\hline Thiopental (N01AF03) & 1 & 0.5 & 19 & 3.7 & 20 & 2.8 \\
\hline Phentanyl (N02AB03) & 1 & 0.5 & 17 & 3.3 & 18 & 2.5 \\
\hline Diazepam (N05BA01) & 5 & 2.7 & 11 & 2.1 & 16 & 2.3 \\
\hline Remiphentanyl (N01AH06) & - & - & 7 & 1.3 & 7 & 1.0 \\
\hline Lorazepam (N05BA06) & 1 & 0.5 & 5 & 1.0 & 6 & 0.8 \\
\hline Clonazepam (N03AE01) & - & - & 4 & 0.8 & 4 & 0.6 \\
\hline Ketamine (N01AX03) & - & - & 4 & 0.8 & 4 & 0.6 \\
\hline Morphine (N02AA01) & - & - & 3 & 0.6 & 3 & 0.4 \\
\hline Other & 1 & 0.5 & 12 & 2.3 & 13 & 1.8 \\
\hline Total & 188 & 100.0 & 520 & 100.0 & 708 & 100.0 \\
\hline
\end{tabular}

SD: Surgical Department, ID: Internal Department

\section{CONCLUSION}

The use of DSC that has a significant property due to specific prescription requirements, in surgical procedures and postoperative analgesia is inevitable. It is noted that CDP with a surgical diagnosis is not only being prescribed by SD physicians but also by ID members in a significant amount. Study findings regarding who wrote this type of medication more often, and which is the more frequently prescribed drug, offers important clues to the use of DSC. It is expected that findings of this study will be of benefit for the current, frequent changes and regulations in the health care system that also include prescriptions.

Peer-review: Externally peer-reviewed.

Author Contributions: Study concept and design - A.A., M.Ü.U., I.T., H.Y., D.D.; Acquisition of data - A.A., M.Ü.U., I.T., H.Y.; Analysis and interpretation of data - A.A., M.Ü.U., I.T., H.Y.; Preparation of the manuscript - A.A., M.Ü.U.; Statistical analysis - A.A., M.Ü.U., D.D.

Conflict of Interest: No conflict of interest was declared by the authors.

Financial Disclosure: The authors declared that this study has received no financial support.

\section{REFERENCES}

1. Official Gazette of Turkish Republic. 1961 Regulation on Narcotic Substances. 12 Mayıs 1967, Sayı:12596, Başbakanlık Basımevi, Ankara.

2. Official Gazette of Turkish Republic. 1971 Regulation on Psychotropic Substances. 07 Mart 1981, Sayı: 17272, Başbakanlık Basımevi, Ankara.
3. Official Gazette of Turkish Republic. 1988 United Nations Regulation against smuggling of Narcotics and Psychotrpic Substance. 25.11.1995, Sayı: 22474, Başbakanlık Basımevi, Ankara.

4. Akıcı A, Oktay Ş, Kayaalp SO. Prescription writing rules and rational drug use. Kayaalp SO, editör. Akılcıl Tedavi Yönünden Tıbbi Farmakoloji. 13. Baskı. Ankara: Pelikan Yayıncılık, 2012. p.140-54.

5. Official Gazette of Turkish Republic. Regulation on the Use of Red, Green and Controlled Drugs . 29 Mayıs 1985, Sayı: 5768, Başbakanlık Basımevi, Ankara.

6. Official Gazette of Turkish Republic. Regulation on Sales/Disposal of Controlled Substances. 19 Kasım 2003, Sayı: 48192, Genelge No: 2003/137, Başbakanlık Basımevi, Ankara.

7. Navil F. Sethna. Pediatric Postoperative Pain Management. Churchill Livingstone, New York, 1999; 485-518.

8. Parker AJ. The appropriate use of opiates in chronic pain. The Journal of Clinical Psychiatry 2012; 73: 8. [CrossRef]

9. Ogboli-Nwasor E, Sule ST, Yusufu LM. Pattern of postoperative pain management among adult surgical patients in a low-resource setting. J Pain Res 2012; 5: 117-20. [CrossRef]

10. Han H, Kass PH, Wilsey BL, Li CS. Individual and county-level factors associated with use of multiple prescribers and multiple pharmacies to obtain opioid prescriptions in california. PloS one 2012; 7: 9.

11. Fredheim OMS, Skurtveit $S$, Breivik $H$, Borchgrevink PC. Increasing use of opioids from 2004 to 2007 - pharmacoepidemiological data from a complete national prescription database in Norway. European journal of pain (London, England) 2010; 14: 289-94. [CrossRef]

12. Demircan D, Gulmez E, Donertas B, Topcu I, Yilmaz H, Berkman $\mathrm{K}$, et al. Use of drugs subject to controlled prescriptions: a retrospective analysis. Balkan Med J (in pres).[doi: 10.5152/balkanmedj.2012.073]. [CrossRef]

13. Kehlet $H$, Dahl JB. Anaesthesia, surgery, and challenges in postoperative recovery. Lancet 2003; 362: 1921-8. [CrossRef]

14. Tocher J, Rodgers S, Smith MA, Watt D, Dickson L. Pain management and satisfaction in postsurgical patients. J Clin Nurs 2012; 21: 3361-71. [CrossRef] 
Akıcı et al.

Controlled drugs in surgery

15. Buckenmaier CC. The role of pain management in recovery following trauma and orthopaedic surgery. J Am Acad Orthop Surg 2012; 20: 35-8. [CrossRef]

16. Sarıhan E, Kadıoğlu E, İğde FA. Cancer pain, treatment principles and World Health Organization stepwise pain treatment. Nobel Med 2012; 8: 5-15.

17. Stiefel F, Morant R, Radziwill A, Senn HJ. Attitudes of Swiss physicians in prescribing opiates for cancer pain. upport Care Cancer 1993; 1: 259-62. [CrossRef]

18. Benhamou D, Berti M, Brodner G, De Andres J, Draisci G, MorenoAzcoita M, et al. Postoperative Analgesic THerapy Observational Survey (PATHOS): a practice pattern study in 7 central/southern European countries. Pain 2008; 136: 134-41. [CrossRef]

19. de Vries TP, Henning RH, Hogerzeil HV, Bapna JS, Bero L, Kafle KK, et al. Impact of a short course in pharmacotherapy for undergraduate medical students: an international randomised controlled study. Lancet 1995; 346: 1454-7. [CrossRef] 